\title{
Assessment and Management of Lateral Elbow Pain in Physiotherapy Clinical Practice: an Italian National Survey
}

\author{
T. Cioce ${ }^{1}$, D. Pennella ${ }^{2,3}$, F. Brindisino 2,3, L. Di Filippo ${ }^{3,4}$, M. Salomon ${ }^{3}$, F. Maselli5 \\ 1 Casa di Cura - Villa delle Terme, Florence, Italy \\ 2 Department of Medicine and Health Science Vincenzo Tiberio, University of Molise, Campobasso, Italy \\ 3 Department of Clinical Science and Translational Medicine, University of Rome Tor Vergata, Rome, Italy \\ ${ }^{4}$ FisioAnalysis Maedica, Alessandria, Italy \\ 5 Department of Neurosciences, Rehabilitation, Ophthalmology, Genetic and Maternal Infantile Sciences \\ (DINOMGI), Campus of Savona, University of Genoa, Italy
}

\author{
CORRESPONDING AUTHOR: \\ Filippo Maselli \\ Department of Neurosciences, \\ Rehabilitation, Ophthalmology, \\ Genetic and Maternal Infantile Sciences \\ (DINOMGI) \\ Campus of Savona \\ University of Genoa \\ via Balbi 5 \\ 16126 Genoa, Italy \\ E-mail: masellifilippo76@gmail.com
}

DOI:

10.32098/mltj.04.2020.18

LEVEL OF EVIDENCE: 4

\begin{abstract}
SUMMARY
Introduction. Lateral Elbow Pain (LEP) represents a disabling condition with a 1-3\% prevalence in general population and a low spontaneous resolution rate within a year. This study investigated the methods of assessment and management of LEP in a sample of physiotherapists in relation to their level of experience.

Methods. We conducted a cross sectional survey consisting of 12 questions. The investigation lasted 2 months and was disseminated through the informative channels of the Italian Physiotherapists Association and by e-mail. The percentage of responses was expressed for different levels of experience in terms of years of work and number of patients with LEP seen in 1 month. Data were analyzed with the SPSS software.

Results. 1405 responses were collected. For LEP management, Psycho-Social Factors (PSFs) are more considered by the interviewees with few years of clinical practice than those who have worked for several years $\left(p<0.001 ; \chi^{2}=36.795\right)$; surgery is less considered as a therapeutic option by professionals who see $0-1$ patients per month than those who see much more patients $\left(\mathrm{p}<0.001 ; \chi^{2}=20.521\right)$. The percentage of use of manual therapy $\left(\mathrm{p}=0.017 ; \chi^{2}=32.901\right)$ and the use of the Maudsley and SALT tests $\left(\mathrm{p}=0.012 ; \chi^{2}=65.360\right)$ result higher in the group that sees more than 3 patients per month; corticosteroid infiltrations are not considered useful by those who see more than 3 patients per month compared to those who see 1 patient or none $\left(\mathrm{p}<0.001 ; \chi^{2}=43.632\right)$.

Conclusions. Despite being aware of the new evidence on the etiology of LEP, only a small percentage of interviewed physiotherapists resort to adequate and specific assessment tools. Clinicians should update their patient management options to better act on the PSFs and mostly consider a multidisciplinary approach to LEP disorders.
\end{abstract}

KEY WORDS

Lateral Epicondylitis; assessment; cross sectional survey; elbow; lateral elbow pain; physiotherapy.

\section{INTRODUCTION}

Lateral Elbow Pain (LEP), a condition also known as tennis elbow, epicondylalgia, lateral epicondylitis or tendinosis, is a very common disabling condition (1): $40 \%$ of the general population experiences this problem at least once in lifetime. The most affected category seems to be manual work- ers with high demands for strength, repetitive movements, vibrations and uncomfortable postures (1), in an age group between $35-50$ years $(2,3)$.

This condition was described for the first time in medical literature by Runge in 1873 (4) as a chronic symptomatic degeneration of the extensor tendons of the wrist (3) and 
the most involved component is the origin of the common tendon itself, on the lateral epicondyle of the humerus. LEP can also be considered a "tendinosis", which means a chronic symptomatic degeneration of the common tendon of the extensor muscles of the forearm at the level of the lateral epicondyle of the humerus (5). To date, in literature, the term LEP underlies two different components as the origin of pain: extra-articular and intra-articular of the elbow $(5,6)$. Clinically, LEP presents itself as pain projected on the dorsal surface of the forearm and reduction of the gripping force, mainly present in the dominant limb (1). It often causes severe limitation of daily and sport activities $(1,7)$. Generally, spontaneous resolution rate within a year is low: $50 \%$ of symptoms persist for up to 18 months and $20 \%$ recur in the 3-5 years following the onset (8). This entails significant socio-economic costs (9): the resulting absenteeism from work was estimated to cost $\$ 27$ million in 2012 in the UK alone (10), indeed.

In the last twenty years, numerous studies have considered an integrated model for the assessment of musculoskeletal pathologies (Bio-Psycho-Social-BPS model) to explain the dichotomy between linear and gradual healing of the injured tissue and the non-linear resolution of painful symptoms $(11,12)$. By linear healing is meant the foreseen period for tissue healing which includes (13):

- an inflammatory phase lasting 2-4 days;

- a proliferative phase lasting about 6 weeks for the tendons (13), in which occurs collagen synthesis and deposition, the removal of inflammation mediators and the growth of the capillary vessel in the area, with a significative increase in fibroblast activity and the development of granulation tissue (13).

In particular, in LEP, to explain the persistence of pain beyond these expected times, Coombes and colleagues in 2009 (14) developed a new model, which took into account the tendon structural pathology, the consequent mechanisms that alter motor control and the biochemical justification which leads patients to persistent pain in absence of tendon pathology (14).
As far as clinical evaluation is concerned, numerous tests are cited in literature, although there is a low presence of articles with accurate descriptions of them $(15,16)$. The most cited are: the Maudsley test (Hsu, Moen, Levine, and Ahmad, 2012) (resisted extension of the third finger with elbow flexed at $90^{\circ}$ and pronated forearm; it results positive for pain appearance on the lateral aspect of the joint), the Cozen test (17) (fully extended elbow and forearm in pronation; the patient is asked to resist an opposing force manually applied on the hand, closed in a punch with extended wrist and radial deviation; the test is considered positive if it reproduces pain or other symptoms in the lateral epicondyle area). Pain-Free Grip test is also described (PFG) (18): it reproduces patient's pain (18) and measures the reduction of the gripping force (18). The Supination and Antero-Lateral pain Test (SALT) (5) and the Posterior Elbow Pain by Palpation-Extension of the Radio-capitellar joint (PEPPER) (5) are two recently described diagnostic tests, instead: they evoke the pain generated, with higher probability, from intra-articular structures. Table I summarizes the diagnostic accuracy values of the aforementioned tests.

During the evaluation phase, in addition to the clinical tests, it is useful to use rating scale and questionnaires to quantify entities of changes following a possible treatment. In literature, described tools for LEP are: Disability of the Arm, Shoulder and Hand (DASH) (19) for the upper limb, in general, and the Patient Rated Tennis Elbow Evaluation (PRTEE) (20), which is much more specific for the elbow; the Center for Epidemiological Studies Depression Scale (CES-D) and the Hospital Anxiety and Depression Scale (HADS) are two scales which investigate patient's psychological state $(21,22)$.

Over the past decade, over 40 different techniques used in physiotherapy for the treatment of LEP have been described in over 250 clinical studies; all concluded that there is no ideal or unique treatment (23).

Given these uncertainties and due to the absence of consistent data relating to the Italian territory, the aim of this study was to investigate the methods and approaches used by Italian physiotherapists, both in the management and

Table I. Diagnostic accuracy of elbow assessment test.

\begin{tabular}{lllll}
\hline Test & Sensibility $\%$ & Specificity $\%$ & PPV $\%$ & NPV $\%$ \\
\hline Maudsley test & 88 & 0 & 85 & 0 \\
\hline Cozen test & 84 & 0 & 84 & 0 \\
\hline SALT & 87.50 & 50 & 87.50 & 50 \\
\hline PEPPER & 37.50 & 100 & 100 & 28.57 \\
\hline
\end{tabular}

NPV: Negative Predictive Value; PEPPER: Posterior Elbow Pain by Palpation Extention of the Radio-capitellar joint; PPV: positive predictive value; SALT: Supination and Antero-Lateral Pain Test; \%: percentage. 
in the assessment of LEP, in relation to the level of their professional experience, in terms of years of work and the number of patients with LEP seen in 1 month. Moreover, we assessed their adherence to the most recent scientific evidence-based literature.

Considering LEP as a disabling condition with high recurrence rates, it could be helpful to understand and observe the management activities of Italian physiotherapists in evaluating and treating such clinical condition in such a way to fill any gaps in the spectrum of Italian physiotherapist's competence.

On the other hand, concrete and favorable answers could be given in relation to the patients' requests, for example in the context of reduction of painful symptoms, dejection of direct and indirect costs related to this condition, restoration of better quality of life. To the authors' knowledge, this is the first study to investigate this field.

\section{METHODS}

\section{Study design}

The study was designed as a cross-sectional observational study based on the administration of questionnaires both directly on paper and in web mode, based on the guidelines of Strengthening the Reporting of Observational Studies in Epidemiology (STROBE) (for the paper questionnaire) (24) and the Checklist for Reporting Results of Internet E-Surveys (CHERRIES) (for the online questionnaire) (25). The questionnaire was designed with reference to similar questionnaires $(26,27)$ and with the consent of 10 experts OMPT physiotherapists (Orthopedic Manipulative Physical Therapist) with at least 5 years after specialization experience.

\section{Survey structuring}

The questionnaire consisted of 12 questions (Appendix 1Questionnaires), all designed with multiple answers, with a completion time estimated by the software of 3 minutes and distributed in 1 single page. Authors chose to structure the survey in this way since it has been shown that, although the "ideal" duration of a survey varies according to the topic, population and context, a positive impact on completion rates of the survey was found if minimum length is guaranteed (one or two pages, at most) $(28,29)$. Questions identified with Q5, Q8 and Q9 had, as additional answer field the choice "Other", with the obligation to specify alternative answers to those present in the text box. The first three questions (Q1-Q3) collected information on the professional sphere and were used to understand the level of work experience of our target population (years of work, work setting, number of patients with LEP assessed in a month). The other nine questions (Q4-Q12) were specific for the assessment and management of LEP, in particular regarding to which anatomical structures were considered during patient's evaluation, which were the most commonly used clinical tests, which considerations the physiotherapists have towards psychosocial factors, the weight of the instrumental diagnostic investigations and the role of surgical and/or infiltrative treatment.

The survey was analyzed by a panel of ten experts physiotherapist with extensive experience in survey design in order to increase its internal consistency and technical functionality of the electronic questionnaire (30); all physiotherapists were professionals with more than 5 years of experience in the treatment of upper limb pathologies and, in particular, of the elbow district. The survey could be checked and modified at the end of the compilation before sending it. Experts worked independently on the questionnaire and agreed on the final version of the questionnaire with respect to the terms, feedback, questions and structure of the survey, which was gradually enriched with their suggestions.

When agreement was reached, a preliminary version of the survey was administered to a sample of 20 physiotherapists to increase the content validity of the survey itself. When the pilot internship was completed, experts conducted a one-to-one interview with the 20 physiotherapists about the possible difficulties encountered during the survey (for example, identifying questions which required further explanation, too difficult question formulation, possibility of respondents seemed to be confused in answers). During the pilot stage, no ambiguous questions emerged, the words used were simple and easy to understand, therefore no change was necessary.

\section{Ethical approving}

This study was approved by the Ethics Committee of the Local Health Authority of Lecce on March 7, 2019 with protocol number 30/2019. The complete version of the survey, in Italian and English language, is available as supplementary material (Appendix 1- Questionnaires).

\section{Sampling and recruitment}

The questionnaire was addressed to all professionals with a degree in physiotherapy and practitioners in Italy. The questionnaire was spread through:

- informative channels of the Italian Physiotherapists Association (A.I.F.I); 
- social media (Facebook and WhatsApp);

- direct e-mail contacts of physiotherapists.

An electronic invitation form and an information letter were provided to all participants (Appendix 2 - Information letter). The questionnaire could be only completed once per email address. Before starting the compilation of the questionnaire, written informed consent was requested.

\section{Data collection}

The survey was available on the SurveyMonkey ${ }^{\circledR}$ platform (www.surveymonkey.com) for 2 months from March 20th to May 20th. Two months are considered a reasonable time for data acquisition (31), also because no further request for completing the questionnaire has been registered after this date. The estimated sample size was 1050 respondents, calculated with a dedicated software within the Sample Size Calculator platform (https://www.surveymonkey.com/mp/sample-size-calculator), considering a $95 \%$ Confidence Level, a margin of error of 3\%. Target population has been identified in all the Italian physiotherapists surveyed by AIFI, with a number equal to 65000 (https:// aifi.net/censimento-aifi-italia-65 mila-fisioterapisti/). The collected data were stored in the software, protected by an access password.

\section{Analytical procedures}

The SurveyMonkey ${ }^{\circledR}$ software allowed us to extrapolate the raw data and export it into Microsoft Excel. The data were analyzed with SPSS Statistical Software (Version 25.0. Armonk, NY: IBM Corp).

The demographic information was entirely analyzed and used to define the characteristics of the studied population, the level of experience and the number of patients seen in 1 month. Each question relating to the assessment and management of the patient with LEP (Q4-Q12) was evaluated in relation to the level of experience of the subject interviewed (Q1-Q3). The percentage of responses for different levels of experience was expressed through proportions.

Based on the type of data being analyzed (dichotomous and categorical variables), the Chi-Square Test $\left(\chi^{2}\right)$ was chosen to highlight the presence of significant differences in the comparison between the various proportions. For this test, a p-value $<0.05$ was assumed as significant.

Subsequently, to identify the responsible couples for this existing difference, the z-test was used with a p-value adjusted according to the "Bonferroni correction for multiple comparisons".

\section{RESULTS}

A total of 1405 responses were collected with a $100 \%$ completion rate and an average time taken of 3 minutes and 25 seconds to fill the question form. Most of the responses to the survey were collected during the first week, the number drastically reduced in the following 3 weeks and then peaked again in the fifth week (when the questionnaire was disseminated by the A.I.Fi. informative channels). The data collected showed that the majority of respondents $(32.23 \%)$ have been working as physiotherapists for less than 5 years, in a private study $(63.46 \%)$ and visit less than 2 LEP patients per month (table II).

Most of respondent $(78.23 \%$ ) considered both the insertion tendon of the extensor muscles of the carpus and fingers as well as the myo-tendon junction of the extensor muscles of the carpus and fingers and the humerus-radial and radio-ulnar joint responsible for pain in a patient with LEP.

The most used clinical tests during the evaluation, in order of frequency, were: the Cozen Test $(63.81 \%)$, the Maudsley Test $(46.82 \%)$, SALT $(23.79 \%)$ and PEPPER $(21.50 \%)$ Test. Almost all the respondents $(88.95 \%)$ considered that Psychosocial Factors (PSFs) can significantly influence the natural history and management of the patient with LEP. Of these, most adopt multiple strategies for managing psychosocial factors (patient education, cognitive behavioral approach).

The rating scales and questionnaires mainly most used with this type of patient were the DASH $(57.81 \%)$ and the PRTEE (38.12\%). Other response have been entered $(19.54 \%)$, using option box "Other".

Table II. Information on the professional dimension.

\begin{tabular}{ll}
\hline Q1-Q3 & $\mathbf{n = 1 4 0 5}$ \\
\hline Year of clinical practice & $\mathbf{\%}$ \\
\hline $0-5$ & 32.23 \\
\hline $5-10$ & 28.94 \\
\hline $10-20$ & 23.93 \\
\hline$>20$ & 19.90 \\
\hline Setting & $\%$ \\
\hline Private study & 63.46 \\
\hline Nursing home & 5.89 \\
\hline Hospital & 12.49 \\
\hline Affiliated clinica & 18.16 \\
\hline Number of patients/month & $\%$ \\
\hline $0-1$ & 46.59 \\
\hline $1-2$ & 29.53 \\
\hline $2-3$ & 14.48 \\
\hline$>3$ & 9.39 \\
\hline
\end{tabular}

LEP: Lateral Elbow Pain; n: respondents; \%: percentage. 
Significant $63.96 \%$ of respondents considered instrumental diagnostic investigations (Magnetic Resonance Imaging, Computed Tomography, Ultrasonography) useful in the presence of signs and symptoms that suggest a pathology of non-physiotherapeutic competence. A reduced percentage expressed specific cases for which the use of diagnostic investigations is relevant or consider these investigation tools "always" or "useful".

Surgery intervention is considered a therapeutic alternative in case of persistent LEP only by $29.54 \%$ of physiotherapists. Most of the physiotherapists $(38.31 \%)$ didn't consider corticosteroid infiltrations to be useful in a patient with LEP, the others considered them useful only in a certain phase of the pathology.

Most respondents (37.61\%) used Therapeutic Exercise (TE) combined with Manual Therapy (MT) as proper conservative approach; smaller percentages used a unimodal approach. All the results to these answers were summarized in table III.

Analyzing the methods of assessment and management of LEP (Q4-Q12) in relation to the level of experience of physiotherapists, it emerged that:

- who has more years of clinical practice (> 20), did not consider that psychosocial factors may influence the natural history and management of the patient with LEP with a significantly higher percentage than all the others $\left(\mathrm{p}<0.001 ; \chi^{2}=36.795\right)$ (figure 1$)$;

- there was no significant difference between the groups with several years of experience and the consideration of surgery as a therapeutic alternative in persistent LEP $\left(\mathrm{p}=0.258 ; \chi^{2}=4.031\right)$ (figure 2$)$;

- the use of the Maudsley and SALT clinical tests was significantly greater in the group that saw more than 3 patients per month compared to " $0-1$ " and " $1-2$ " $\left(\mathrm{p}=0.012 ; \chi^{2}=65.360\right)($ table IV $)$

- those who saw $0-1$ patients in 1 month considered surgery less useful than those who saw more patients $(\mathrm{p}<0.001$; $\left.\chi^{2}=20.521\right)$ (figure 3);

- in relation to the question "Do you consider corticosteroid infiltrations useful in a patient with LEP?", the answer "No" was significantly greater in the group "over 3" compared to " $0-1$ "; the answer "I don't know" was significantly greater in the group " $0-1$ " than in " $2-3$ " and "beyond 3"; the answer "Yes, in chronic patient" was significantly greater in the group " $2-3$ " compared to "0-1" and "1-2" ( $\left.\mathrm{p}<0.001 ; \chi^{2}=43.632\right)$ (figure 4);

- the percentage of TM use was significantly higher in the group that saw more than 3 patients in 1 month compared to the group that saw $0-1$ and $1-2$ patients in 1 month ( $\left.\mathrm{p}=0.017 ; \chi^{2}=32.901\right)$ (figure 5).
Table III. Assessment and management of the patient with LEP. Q4-Q12

Anatomical structure that cause pain $\%$

CED and EC tendon 10.63

CED and EC myo-tendinous junction $\quad 6.75$

Joint and surroundings tissues 4.38

All mentioned structures $\quad 78.23$

Clinical test used $\%$

Cozen 63.81

Maudsley 46.82

SALT 23.79

PEPPER 21.50

Others 16.91

Considerations on PSFs $\%$

Yes 88.95

No 11.05

Used strategies in the management of PSFs $\quad \%$

Pain neurophysiology education 28.69

Cognitive-behavioral approach 9.43

Encouragmente on active life style $\quad 28.62$

All mentioned 60.22

Evaluation scale and questionnaires $\%$

PRTEE 38.12

DASH 57.81

\begin{tabular}{ll}
\hline CES-D & 2.55 \\
\hline HADS & 5.02 \\
\hline Others & 19.54 \\
\hline Usefulness of diagnostic investigation & $\%$
\end{tabular}

(CT, MRI, USI)

\begin{tabular}{ll}
\hline Never & 1.51 \\
\hline Always & 5.74 \\
\hline Instability & 8.97 \\
\hline Visible acute signs of inflammation & 5.81 \\
\hline Non-physiotherapic competence pathology & 63.96 \\
\hline Non-feasible conservative treatmente & 12.28 \\
\hline Others & 1.72 \\
\hline Consideration on surgery in LEP > 6 months & $\%$ \\
\hline Yes & 29.54 \\
\hline No & 70.46 \\
\hline Usefulness of corticosteroids injections & $\%$ \\
\hline No & 38.31 \\
\hline Always & 0.65 \\
\hline Acute phase & 16.71 \\
\hline LEP $>6$ months & 23.39 \\
\hline
\end{tabular}




\begin{tabular}{|c|c|}
\hline \multicolumn{2}{|l|}{ Q4-Q12 } \\
\hline Anatomical structure that cause pain & $\%$ \\
\hline I don't know & 20.95 \\
\hline Conservative treatment & $\%$ \\
\hline $\mathrm{TE}$ & 7.78 \\
\hline MT & 12.75 \\
\hline $\mathrm{B}$ & 1.08 \\
\hline $\mathrm{TE}+\mathrm{MT}$ & 37.61 \\
\hline $\mathrm{TE}+\mathrm{B}$ & 2.81 \\
\hline $\mathrm{MT}+\mathrm{B}$ & 4.90 \\
\hline $\mathrm{TE}+\mathrm{MT}+\mathrm{B}$ & 33.07 \\
\hline \multicolumn{2}{|l|}{ Q4-Q12 } \\
\hline Anatomical structure that cause pain & $\%$ \\
\hline CED and EC tendon & 10.63 \\
\hline CED and EC myo-tendinous junction & 6.75 \\
\hline Joint and surroundings tissues & 4.38 \\
\hline All mentioned structures & 78.23 \\
\hline Clinical test used & $\%$ \\
\hline Cozen & 63.81 \\
\hline Maudsley & 46.82 \\
\hline SALT & 23.79 \\
\hline PEPPER & 21.50 \\
\hline Others & 16.91 \\
\hline Considerations on PSFs & $\%$ \\
\hline Yes & 88.95 \\
\hline No & 11.05 \\
\hline Used strategies in the management of PSFs & $\%$ \\
\hline Pain neurophysiology education & 28.69 \\
\hline Cognitive-behavioral approach & 9.43 \\
\hline Encouragmente on active life style & 28.62 \\
\hline All mentioned & 60.22 \\
\hline Evaluation scale and questionnaires & $\%$ \\
\hline PRTEE & 38.12 \\
\hline DASH & 57.81 \\
\hline CES-D & 2.55 \\
\hline HADS & 5.02 \\
\hline Others & 19.54 \\
\hline $\begin{array}{l}\text { Usefulness of diagnostic investigation } \\
\text { (CT, MRI, USI) }\end{array}$ & $\%$ \\
\hline Never & 1.51 \\
\hline Always & 5.74 \\
\hline Instability & 8.97 \\
\hline Visible acute signs of inflammation & 5.81 \\
\hline Non-physiotherapic competence pathology & 63.96 \\
\hline
\end{tabular}

\begin{tabular}{ll}
\hline Q4-Q12 & \\
\hline Anatomical structure that cause pain & $\%$ \\
\hline Non-feasible conservative treatmente & 12.28 \\
\hline Others & 1.72 \\
\hline Consideration on surgery in LEP $>$ 6 months & $\%$ \\
\hline Yes & 29.54 \\
\hline No & 70.46 \\
\hline Usefulness of corticosteroids injections & $\%$ \\
\hline No & 38.31 \\
\hline Always & 0.65 \\
\hline Acute phase & 16.71 \\
\hline LEP $>6$ months & 23.39 \\
\hline I don't know & 20.95 \\
\hline Conservative treatment & $\%$ \\
\hline TE & 7.78 \\
\hline MT & 12.75 \\
\hline B & 1.08 \\
\hline TE + MT & 37.61 \\
\hline TE + B & 2.81 \\
\hline MT + B & 4.90 \\
\hline TE + MT + B & 33.07 \\
\hline
\end{tabular}

B: bracing; CES-D: Center for Epidemiological Studies Depression Scale; CT: Computed Tomography; DASH: Disabilities of the Arm, Shoulder and Hand; EC: Extensor of the carpus; ECD: Extensor common digits; TE: Therapeutic Exercises; PSFs: Psycho-social factors; HADS: Hospital Anxiety and Depression Scale; LEP: Lateral Elbow Pain; MRI: Magnetic Resonance Imaging; MT: Manual Therapy; PEPPER: Posterior Elbow Pain by Palpation Extension of the Radio-capitellar joint; PRTEE: Patient-Rated Tennis Elbow Evaluation; SALT: Supination and Antero-Lateral Pain Test; TE: Therapeutic Exercise; USI: Ultrasound Imaging; \%: percentage.

\section{DISCUSSIONS}

The purpose of this study was to find out which LEP assessment and management strategies are in relation to the level of experience of the Italian physiotherapists. In 2010, McDermid and his team (32) conducted a similar study in Canada concluding that their clinical practice was aligned with literature despite the lacking an optimal definition of education and exercise as tools rehabilitation (32). From the analysis of the results of the present study, it emerged that about half of the sample treats none or at most one patient per month with this problem: this may be defined as a general poor experience regarding the LEP by the respondents. However, most of the respondent, updated with the most recent evidence-based literature on the etiology of LEP, believe that the main cause of the problem is multifactorial $(5,6,14)$, recognizing as pathogenic "noxa" not only the 


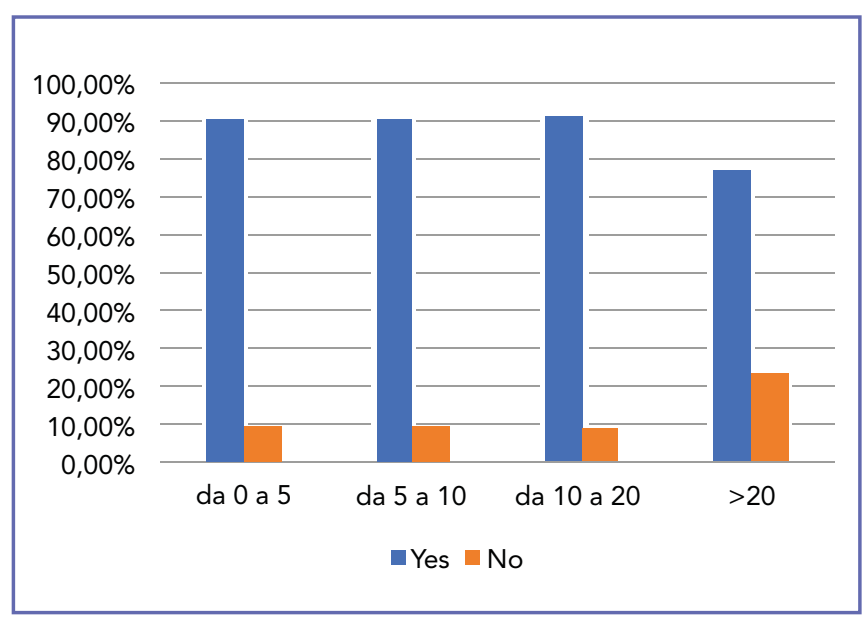

Figure 1. Comparison of proportions between considerations on PSFs and numbers of years of clinical practice. $(p<0.001$; $\left.\chi^{2}=36.795\right)$.

*: "No" significantly different between "> 20" and "0-5"; $\wedge$ : No significantly different between "> 20" and "10-20"; †: No significantly different between "> 20" and "5-10".

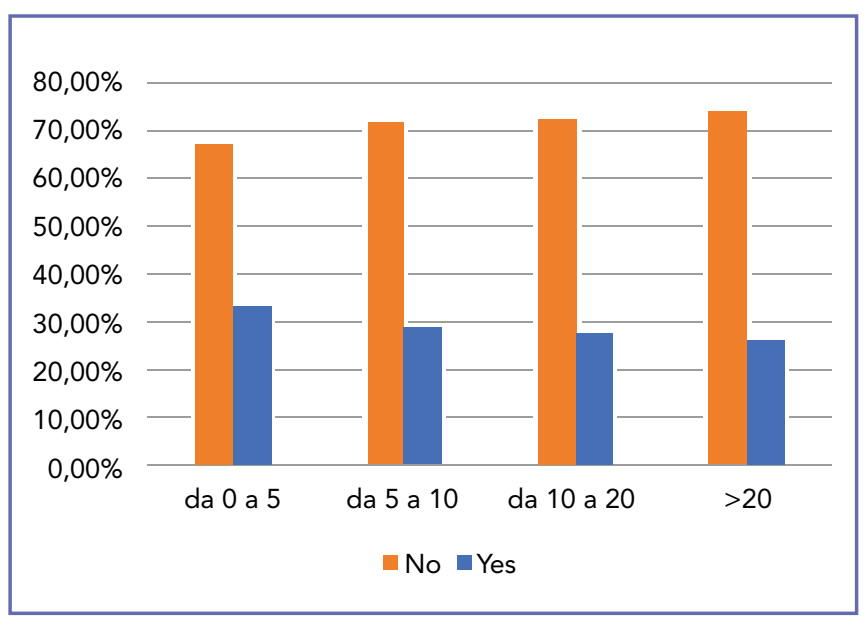

Figure 2. Comparison between proportions of surgery considerations and years of clinical practice. Do you consider corticosteroid infiltrations useful in a patient with LEP? $p=0.258 ; \chi^{2}=4.031$.

Table IV. Comparison between proportions of clinical tests and patients/months.

\begin{tabular}{|c|c|c|c|c|c|}
\hline & & $0-1$ & $1-2$ & $2-3$ & $>3$ \\
\hline \multirow[t]{15}{*}{ Q5 } & None & $14.6 \%$ & $15.5 \%$ & $16.3 \%$ & $15.1 \%$ \\
\hline & $\mathrm{C}$ & $22.9 \%$ & $23.5 \%$ & $17.8 \%$ & $13.7 \%$ \\
\hline & $\bar{M}$ & $11.5 \%$ & $11.4 \%$ & $11.9 \%$ & $16 \%$ \\
\hline & $\mathrm{S}$ & $4.2 \%$ & $5.6 \%$ & $3.5 \%$ & $4.6 \%$ \\
\hline & $\mathbf{P}$ & $3.7 \%$ & $4.6 \%$ & $3.5 \%$ & $5.3 \%$ \\
\hline & $\mathrm{C}+\mathrm{M}+\mathrm{S}+\mathrm{P}$ & $7.1 \%$ & $4.9 \%$ & $6.4 \%$ & $4.6 \%$ \\
\hline & $C+M+S$ & $1.4 \%$ & $1 \%$ & $2 \%$ & $0.8 \%$ \\
\hline & $\mathrm{C}+\mathrm{M}$ & $21.7 \%$ & $20.9 \%$ & $24.8 \%$ & $20.6 \%$ \\
\hline & $\mathrm{M}+\mathrm{S}$ & $0.8 \% \wedge$ & $0.2 \% *$ & $2 \%$ & $6.1 \%$ \\
\hline & $\mathbf{M}+\mathrm{S}+\mathrm{P}$ & $0.3 \%$ & $0.5 \%$ & $1 \%$ & $0 \%$ \\
\hline & $\mathbf{S}+\mathbf{P}$ & $4.2 \%$ & $1.7 \%$ & $3 \%$ & $5.3 \%$ \\
\hline & $\mathrm{C}+\mathrm{S}+\mathrm{P}$ & $1,5 \%$ & $1.2 \%$ & $1 \%$ & $0 \%$ \\
\hline & $\mathrm{C}+\mathrm{S}$ & $3.1 \%$ & $5.1 \%$ & $5 \%$ & $4.6 \%$ \\
\hline & $\mathrm{C}+\mathrm{P}$ & $2.5 \%$ & $2.4 \%$ & $1.5 \%$ & $3.8 \%$ \\
\hline & $C+M+P$ & $0.6 \%$ & $1.5 \%$ & $0.5 \%$ & $0 \%$ \\
\hline
\end{tabular}

$\mathrm{p}=0.012 ; \chi^{2}=65.360$

*: "M + S" significantly different between "1-2" and "> 3"; ^: "M + S" significantly different between "0-1" and "> 3"; C=Cozen's Test; M=Maudsley Test; P=PEPPER Test; $\mathrm{S}=$ SALT Test. 


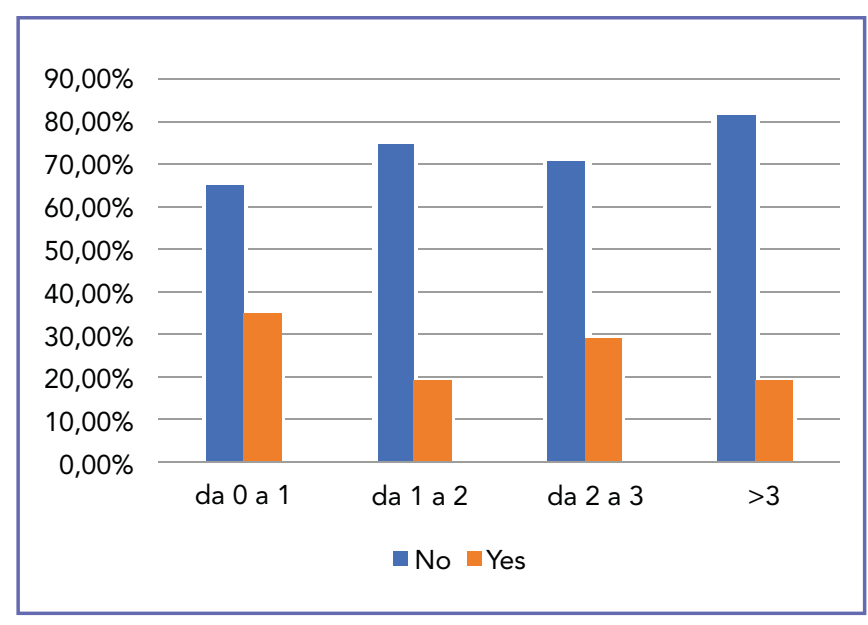

Figure 3. Comparison between proportions of surgery and patients/months. Do you consider corticosteroid infiltrations useful in a patient with LEP? $p<0.001 ; \chi^{2}=20.521$.

*: "No" significantly different between "0-1" and "1-2"; ^: No significantly different between "0-1" and "> 3".

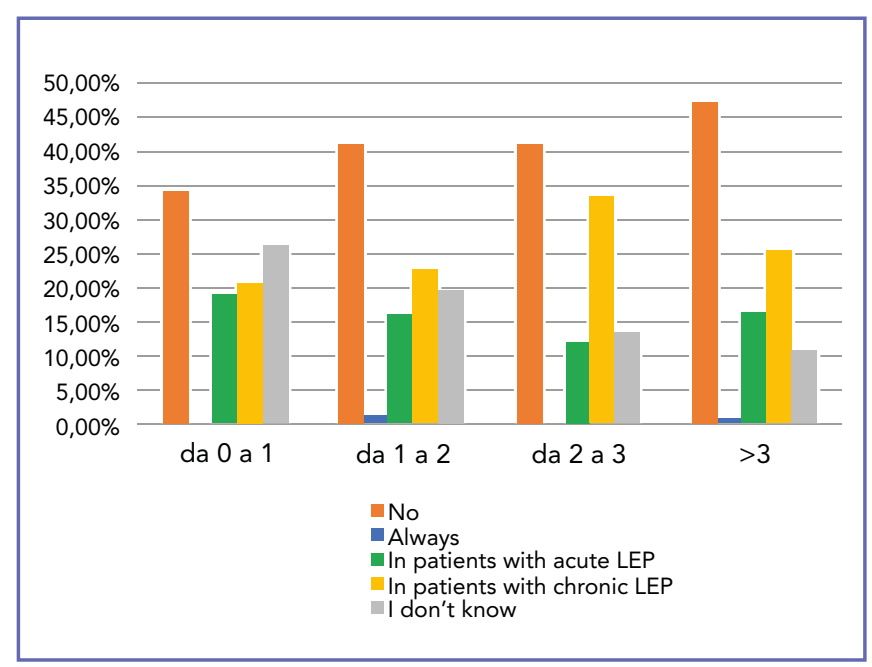

Figure 4. Comparison between proportions of use on corticosteroid injections and patients/months. Do you think corticosteroid infiltrations are useful in a patient with LEP? $\mathrm{P}<$ $0.001 ; \chi^{2}=43.632$.

*: "No" significantly different between "0-1" and "> 3"; $\wedge$ :

"I don't know" significantly different between "0-1" and "> 3"; +: "I don't know" significantly different between "0-1" and "2-3"; $\alpha$ : "Yes, in a chronic patient" significantly different between "0-1" and "2-3"; \#: f: "In a chronic patient" significantly different between "0-1" and "1-2".

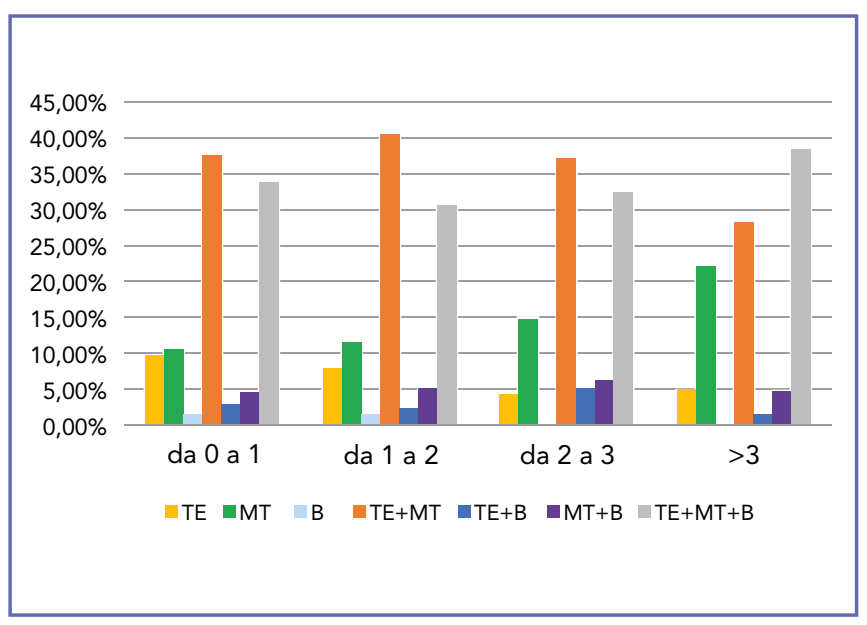

Figure 5. Comparison between proportions of use on corticosteroid injections and number of patients/months. What kind of conservative approach do you use? $p=0.017 ; \chi^{2}=32.901$.

*: "MT" significantly different between " $0-1$ " and "> 3 "; $\wedge$ : "MT" significantly different between "1-2" and "> 3"; B: Bracing; MT: Manual Therapy; TE: Therapeutic Exercise.

tendon component (33-36). In 2017, the study conducted by Arrigoni et al. (6) hypothesized the existence of a specific sub-category of patients, in which the joint complex could play a predominant role in LEP.

Moreover, most of the respondents declared to consider PSFs $(1,37-39)$ to have a significant influence on natural history and in the management of the patient with LEP; they also declared to adopt specific strategies in this regard. Therefore, it was possible to state that the paradigm of the person as a Biopsychosocial entity (BPS) found its clinical application in LEP (40-42). Nevertheless, only very small percentage of professionals resort to evaluation scales like CES-D and HADS. Strategies used for the management of PSFs were often considered and individually used by the respondents, thus not maximizing the effect of a treatment based on the BPS model, which instead promoted the use of multiple treatment strategies and techniques (12).

Regarding clinical tests, SALT and PEPPER tests was proposed in battery only by $11 \%$ of our respondents. It was important to remember that the scientific evidence which demonstrates the usefulness of these two tests was rather recent (5) and this could explain their scarce diffusion.

Saroja in 2014 (43) verified the diagnostic accuracy of the Cozen, Maudsley and Mills tests (table I). Through this questionnaire, it emerged that Cozen and Maudsley tests 
were used more frequently during the evaluation of a patient with a suspected LEP (table III). In a very recent systematic review (44), it emerged that a lot of clinical tests for elbow pathologies were described in literature, but none can provide adequate certainty to rule in or rule out a disease based on sufficient diagnostic accuracy.

Still with regards to assessment procedures, more than half of the respondents declared to mainly use the DASH questionnaire, which is not specific for elbow diseases such as PRTEE. DASH questionnaire was validated in Italian on 108 patients with upper limb problems, of which only 25 affected by epicondylitis (19). It was highly probable that this small number of patients was due to sampling procedure and a low prevalence of LEP disorders compared to other pathologies of the upper limb (45) (table III).

More than half of the respondents considered imaging studies (46-48) as an useful option in the presence of signs and symptoms that suggest a specific pathology of non-physiotherapeutic competence, like cases in which a multidisciplinary assessment would be more appropriate (table II). This could be due to the fact that, in Italy, physiotherapists could not prescribe diagnostic imaging investigations. Therefore, Italian physiotherapist were not used to supplement imaging independently as support for clinical practice. For the management of LEP, we can distinguish between conservative treatment (exercise, manual therapy, brace), injections and surgical treatments. In literature it was recommended to use a conservative approach in the first few months (49) but it would be also appropriate to know how to recognize when conservative treatment was no more effective. This was possible through an accurate medical history and a greater use of dedicated clinical tests $(5,17,18$, 26 ) in order to evaluate alternative strategies for the resolution of symptoms, such as surgery (50-52) and corticosteroid infiltrations (53).

\section{Surgery}

Most respondents $(70.46 \%)$ did not consider surgery as a therapeutic alternative. Regarding this treatment option, a Cochrane systematic review published in 2011 (54) concluded that there is insufficient evidence to support or reject its efficacy due to a small number of studies, a large heterogeneity in the interventions, samples of small size and poor recording of results (54). Common surgical procedures may be performed via percutaneous, arthroscopic, or open approaches (55). A systematic review conducted in 2018 (56) highlights no difference between open surgery and arthroscopy, in terms of efficacy, while it suggests that arthroscopic procedures are associated with less complications (56). Recently, a review of Stover et al. highlighted how Ultrasound-Guided Tenotomy (USGT) represented a minimally invasive treatment option for recalcitrant cases to conservative management (57).

\section{Injections}

Corticosteroid injections showed to produce substantial short-term pain relief $(53,58,59)$, unexpected with the lack of inflammatory biomarkers in tendinopathy $(60,61)$.

A plausible explanation was that placebo and contextual effects (62-64) may be associated. In the long term, no evidence of efficacy was found $(53,58,65)$, due to the high recurrence rates, the risks of fibrosis, adiponecrosis and calcification, as well as the worsening of the clinical course $(62,66)$. In a randomized controlled trial with 1 -year followup (53), recurrence of symptoms was evident in $72 \%$ of patients treated with corticosteroid injection compared to $8 \%$ after physiotherapy treatment (elbow manipulation, therapeutic exercise and education). Coombes et al. in 2009 (67) conducted a clinical study that highlighted how the combined approach (physiotherapy + corticosteroid injections) is preferred to infiltration alone (67).

Although still with few supporting studies, collagen infiltrations were also used and should be considered for future research to enhance available tools to clinicians (68). Several studies have investigated also the use of topically-applied steroids for tendon pain treatment, demonstrating a positive effect on pain in patients with LEP: most advantages reside in their safety application and being well tolerated (69).

\section{Conservative Treatment}

As far as the conservative treatment was concerned, the majority of respondents declared to use a multimodal approach (37.61\% TE + MT, 33.07\% TE + B + MT) (table III).

Appreciating the therapeutic success (7), in 2003 Vincenzino and colleagues (70) considered therapeutic exercise the main strategy for the management of LEP together with additional procedures such as manipulative therapy $(71,72)$ and sports taping $(73)$ techniques. These showed to provide substantial relief from initial pain, to speed up recovery processes and to motivate the patient to adhere to the proposed exercise program. Indeed, a recent systematic review (74) concluded that the majority of consistent findings supported the inclusion of eccentric exercise as part of a multimodal therapy programme due to its effect on improved outcomes in patients with LEP (74).

The protective brace had also proven to be effective for short-term pain reduction $(75,76)$, but no more effective than other strategies such as shock-wave therapy $(77,78)$. 
Therefore, it was not possible to define which is the best treatment for LEP, which must be researched taking into consideration: the experience of the team, the availability of the specific equipment, the clinician experience and expertise and the patient's responses (79).

\section{CONCLUSIONS}

Most of the respondents are updated with the most recent scientific evidence on the etiology of LEP.

It is plausible that, for musculoskeletal pathologies management, in addition to focusing on improving manual skills, clinicians should also update their diagnostic framing skills and their ability of taking in charge patients. It is important that clinicians also take into account that they can, and should, consider and act on the PSFs. In addition, a multidisciplinary type of assessment and management should be increasingly considered, which is hoped for the given complexity of this disorder. The main goal is to avoid mistakes or diagnosis delays, to avoid the development of chronic symptoms in presence of because worst results, to ethically inform patients of the heterogeneity of the treatment and the natural history of LEP. Such behavior can come true only with a consistent improvement of the medical and health culture.

\section{Perspectives}

We have noticed that heterogeneous clinical labelling of lateral elbow pain is found in the literature, also taking into consideration some manuscripts that investigate the psychosocial aspects (40-42).

Therefore, we believe that:

1. a common agreement must be reached soon in scientific community toward the most appropriate terminology used to identify this clinical condition;

2. inclusion criteria used so far in literature could represent a gap to be filled, as probably factors involved in the genesis of the pathology are manifold and could be indicators of specific subgroups with probable different response to the proposed therapeutic pathways;

3. two different subgroups of patient with lateral elbow pain could be identified, where the intra- $(5,6,80)$ or extra-articular (5) component is responsible for most of the symptoms referred by patients, being aware that more likely there is never a single and exclusive involvement of a single structure.

For this reason, we decided to identify a unique terminology to define, respectively, the pain in the elbow with an etiological share of the myo-tendon compartment or of the functional component (non-Specific Lateral Elbow Pain nSLEP) and the pain most likely to be sustained by problems affecting the osteo-articular component, or true structural component (Specific Lateral Elbow Pain - SLEPs) (81). The terminology nSLEP and SLEPs refers to a classification proposal of lateral elbow pain, with its relative decision-making algorithm, inherent to the research strand of this work. Moreover, we decided to follow principles and recommendations in clinical and field Science Research (82).

\section{LIST OF ABBREVIATIONS}

nSLEP: non-Specific Lateral Elbow Pain

B: Bracing

BPS: Bio-Psycho-Social

CES-D: Center for Epidemiological Studies Depression Scale CHERRIES: Checklist for Reporting Results of Internet E-Survey

CT: Computed Tomography

DASH: Disabilities of the Arm, Shoulder and Hand

HADS: Hospital Anxiety and Depression Scale

LEP: Lateral Elbow Pain

MRI: Magnetic Resonance Imaging

MT: Manual Therapy

OMPT: Orthopedic Manipulative Physical Therapist

PEPPER: Posterior Elbow Pain by Palpation-Extension of the Radio-capitellar Joint

PGF: Pain-Free Grip

PRTEE: Patient Rated Tennis Elbow Evaluation

PSFs: Psychosocial Factors

Q: Question

SALT: Supination and Anterolateral Pain Test

SLEPs: Specific Lateral Elbow Pain

SPSS: Statistical Package for Social Science

STROBE: Strengthening the Reporting of Observational Studies in Epidemiology

TE: Therapeutic Exercise

USI: Ultrasound Imaging

\section{ACKNOWLEDGEMENTS}

This project was realized thank to contribution of many people we would like to thank. Therefore, thanks to all the colleagues who participated to the survey and shared it. Thanks to the Italian Association of Physiotherapist AIFI for sharing the survey online.

\section{ETHICS STATEMENT}

This study was approved by the Ethics Committee of Lecce (Italy) on March 7, 2019 with protocol number 30/2019. 
Written informed consent was requested by the used software before starting the questionnaire.

\section{CONFLICT OF INTERESTS}

The authors declare that they have no conflict of interests.

\section{REFERENCES}

1. Shiri R, Viikari-Juntura E. Lateral and medial epicondylitis: role of occupational factors. Best Pract Res Clin Rheumatol 2011;25(1):43-57.

2. Clarke AW, Ahmad M, Curtis M, Connell AD. Lateral Elbow Tendinopathy: correlation of ultrasound findings with pain and functional disability. Am J Sports Med 2010;38:1209-1214.

3. Gold JE, D’Errico A, Katz JN, Gore R, Punnett L. Specific and non-specific upper extremity musculoskeletal disorder syndromes in automobile manufacturing workers. Am J Ind Med 2009;52(2):124-32.

4. Runge F. Zur Genese und Behandlung des Schreibekrampfes. Berliner Klin Wochenschr 1873;10:245-248.

5. Arrigoni P, Cucchi D, Menon A, Randelli P. It's time to change perspective! New diagnostic tools for lateral elbow pain. Musculoskelet Surg 2017;101(2):175-179.

6. Arrigoni P, Cucchi D, D'Ambrosi R, et al. Intra-articular findings in symptomatic minor instability of the lateral elbow (SMILE). Knee Surg Sports Traumatol Arthrosc 2017;25:2255-2263.

7. Bisset LM, Vicenzino B. Physiotherapy management of lateral epicondylalgia. J Physiother 2015;61(4):174-81.

8. Berglund KM, Persson BH, Denison E. Prevalence of pain and dysfunction in the cervical and thoracic spine in person with and without lateral elbow pain. Man Ther 2008;13(4):295-9.

9. Martin JI, Atilano L, Merino J, et al. Predictors of Outcome Following Tenotomy in Patients with Recalcitrant Epicondylopathy. PM R 2019;11(9):979-988.

10. Walker-Bone K, Palmer KT, Reading I, Coggon D, Cooper C. Occupation and epicondylitis: a population-based study. Rheumatology (Oxford) 2012;51(2):305-310.

11. Flor H, Turk DC. Chronic pain: an integrated biobehavioral approach. Seattle: IASP Press 2011. Cogn Behav Pract 2013;20(1):117-118.

12. Gatchel RJ, Peng YB, Peters ML, Fuchs PN, Turk DC. The biopsychosocial approach to chronic pain: scientific advances and future directions. Psychol Bull 2007;133(4):581-624.

13. Enwemeka CS. Connective tissue plasticity: ultrastructural, biomechanical, and morphometric effects of physical factors on intact and regenerating tendons. J Orthop Sports Phys Ther 1991;14(5):198-212.

14. Coombes BK, Bisset L, Vincenzino B. A new integrative model of lateral epicondylalgia. Br J Sports Med 2009;43:252-258.

15. Fairbank SM, Corlett RJ. The role of the extensor digitorum communis muscle in lateral epicondylitis. J Hand Surg $\mathrm{Br}$ 2002;27(5):405-9.

16. Bhargava AS, Eapen C, Kumar SP. Grip strength measurements at two different wrist extension positions in chronic lateral epicondylitis-comparison of involved vs. uninvolved side in athletes and non athletes: a case-control study. Sports Med Arthrosc Rehabil Ther Technol 2010;2:22.

17. Hsu SH, Moen TC, Levine WN, Ahmad CS. Physical examination of the athlete's elbow. Am J Sports Med 2012;40:699-708.

18. Lim EC. Pain free grip strength test. J Physiother 2013;59(1):59.

19. Padua R, Padua L, Ceccarelli E, et al. Italian version of the Disability of the Arm, Shoulder and Hand (DASH) questionnaire. Cross-cultural adaptation and validation. J Hand Surg Br 2003;28(2):179-86.

20. Cacchio A, Necozione S, MacDermid JC, et al. Cross-cultural adaptation and measurement properties of the italian version of the Patient-Rated Tennis Elbow Evaluation (PRTEE) questionnaire. Phys Ther 2012;92(8):1036-45.

21. Fava GA. Assessing depressive symptoms across cultures: Italian validation of the CES-D self-rating scale. J Clin Psychol 1983;39(2):249-51.

22. Vedana L, Baiardi P, Sommaruga M, et al. Clinical validation of an anxiety and depression screening test for intensive in-hospital rehabilitation. Monaldi Arch Chest Dis 2002;58(2):101-6.

23. Sims SE, Miller K, Elfar JC, Hammert WC. Non-surgical treatment of lateral epicondylitis: a systematic review of randomized controlled trials. Hand (NY) 2014;9(4):419-46.

24. Von Elm E, Altman DG, Egger M, Pocock SJ, Gøtzsche PC, Vandenbroucke JP. The Strengthening the Reporting of Observational Studies in Epidemiology (STROBE) Statement: guidelines for reporting observational studies. Int J Surg 2014;12(12):1495-9.

25. Eysenbach G. Improving the quality of Web surveys: the Checklist for Reporting Results of Internet E-Surveys (CHERRIES). J Med Internet Res 2004;6(3):e34.

26. Maselli F, Ciuro A, Mastrosimone R, et al. Low back pain among Italian rowers: A cross-sectional survey. J Back Musculoskelet Rehabil 2015;28(2):365-76.

27. Bahr R, Andersen SO, Løken S, Fossan B, Hansen T, Holme I. Low back pain among endurance athletes with and without specific back loading-a cross-sectional survey of crosscountry skiers, rowers, orienteerers, and nonathletic controls. Spine (Phila Pa 1976) 2004;29(4):449-54.

28. Kellerman SE, Herold J. Physician response to surveys. Am J Prevent Med 2001;20:61-67.

29. Dillman DA. Mail and telephone surveys: The total design method. New York: John Wiley and Sons, 1978.

30. De Leeuw D, Hox J, Dillman D. International Handbook of Survey Methodology (European Association of Methodology Series). New York: Taylor and Francis group, 2008.

31. Littlewood C, Lowe A and Moore J. Rotator cuff disorders: a survey of current UK physiotherapy practice. Shoulder Elbow 2012;4:64-71.

32. MacDermid JC, Wojkowski S, Kargus C, et al. Hand therapist management of Lateral epicondylosis: a survey of expert opinion and practice patterns. J Hand Ther 2010; 23(1):18-30.

33. Antuna SA, O'Driscoll SW. Snapping plica associated with radiocapitellar condromalacia. Arthroscopy 2001;17:491-495.

34. Kim DH, Gambardella RA, Elatrache NS, Yocum LA, Jobe FW. Arthroscopic Treatment of posterolateral elbow impingement from lateral sinovial plicae in throwing athlets and golfers. Am J Sports Med 2006;34:438-444.

35. Wada T, Moriya T, Iba K, et al. Functional outcomes after arthroscopic treatment of lateral epicondylitis. J Orthop Sci 2009; 14:167-174. 
36. Rajeev A, Pooley J. Arthroscopic resection of humeroradial synovial plica for persistent lateral elbow pain. J Orthop Surg 2015;23:11-14.

37. Lee DO, Gong HS, Kim JH, Rhee SH, Lee YH, Baek GH. The relationship between positive or negative phrasing and patients 'coping with lateral epicondylitis. J Shoulder and Elbow Surg 2014;23(4):567-72.

38. Das De S, Vranceanu AM, Ring DC. Contribution of kinesophobia and catastrophic thinking to upper-extremity-specific disability. J Bone Joint Surg Am 2013;95(1):76-81.

39. Bot S, van der Waal JM, Terwee CB, van der Windt DA, Bouter LM, Dekker J. Course and prognosis of elbow complaints: a cohort study in general practice. Ann Rheum Dis 2005;64(9):1331-6.

40. Adams LM, Turk DC. Psychosocial Factors and Central Sensitivity Syndromes. Curr Rheumatol Rev 2015;11(2):96-108.

41. Alizadehkhaiyat O, Fisher AC, Kemp GJ, Frostick SP. Pain, functional disability, and psychologic status in tennis elbow. Clin J Pain 2007;23(6):482-9.

42. Ring D, Kadzielski J, Fabian L, Zurakowski D, Malhotra LR, Jupiter JB. Self-reported upper extremity health status correlates with depression. J Bone Joint Surg Am 2006;88(9):1983-8.

43. Saroja G, Aseer P AL, Venkata SPM. Diagnostic Accuracy of Provocative Tests in Lateral Epicondylitis. Int J Physiother Res 2014;2(6):815-23.

44. Zwerus EL, Somford MP, Maissan F, Heisen J, Eygendaal D, van den Bekerom MP. Physical examination of the elbow, what is the evidence? A systematic literature review. Br J Sports Med 2018;52(19):1253-60.

45. Salaffi F, De Angelis R, Grassi W. Prevalence of musculoskeletal conditions in an Italian population sample: results of a regional community-based study. I. The MAPPING study. MArche Pain Prevalence; Investigation Group (MAPPING) study. Clin Exp Rheumatol 2005;23(6):819-28.

46. Heales LJ, Broadhurst N, Mellor R, Hodges PW, Vicenzino B. Diagnostic ultrasound imaging for lateral epicondylalgia: A case control study. Med Sci Sports Exerc 2014;46:2070-2076.

47. Pasternack I, Tuovinen EM, Lohman M, Vehmas T, Malmivaara A. MR findings in humeral epicondylitis. A systematic review. Acta Radiol 2001;42:434.40.

48. Toit C, Stieler M, Saunders R, Bisset L, Vicenzino B. Diagnostic accuracy of power-doppler ultrasound in patients with chronic tennis elbow. Br J Sports Med 2008;42:872-876.

49. Challoumas D, Clifford C, Kirwan P, Millar NL. How does surgery compare to sham surgery or physiotherapy as a treatment for tendinopathy? A systematic review of randomised trials. BMJ Open Sport Exerc Med 2019;24;5(1):e000528.

50. Wang D, Degen RM, Camp CL, McGraw MH, Altchek DW. Trends in Surgical Practices for Lateral Epicondylitis Among Newly Trained Orthopaedic Surgeons. Dines JS Orthop J Sports Med 2017;5(10):2325967117730570.

51. Monto RR. Tennis elbow repair with or without suture anchors: a randomized clinical trial. Tech Shoulder Elbow Surg 2014;15(3):92-97.

52. Lattermann C, Romeo AA, Anbari A, et al. Arthroscopic debridement of the extensor carpi radialis brevis for recalcitrant lateral epicondylitis. J Shoulder Elbow Surg 2010;19(5):651-6.

53. Bisset L, Beller E, Jull G, Brooks P, Darnell R, Vicenzino B. Mobilisation with movement and exercise, corticosteroid injection, or wait and see for tennis elbow: randomised trial. BMJ 2006;333(7575):939.

54. Buchbinder R, Johnston RV, Barnsley L, Assendelft WJ, Bell SN, Smidt N. Surgery for lateral elbow pain. Cochrane Database Syst Rev 2011;2011(3):CD003525.

55. Tosti R, Jennings J, Sewards JM. Lateral epicondylitis of the elbow. Am J Med 2013;126(4):357.e1.6.

56. Moradi A, Pasdar P, Mehrad-Majd H, Ebrahimzadeh MH. Clinical Outcomes of Open versus Arthroscopic Surgery for Lateral Epicondylitis, Evidence from a Systematic Review. Arch Bone Jt Surg 2019;7(2):91-104.

57. Stover D, Fick B, Chimenti RL, Hall MM. Ultrasound-guided tenotomy improves physical function and decreases pain for tendinopathies of the elbow: a retrospective review. J Shoulder Elbow Surg 2019;28(12):2386-93.

58. Smidt N, van der Windt DA, Assendelft WJ, Devillé WL, Korthals-de Bos IB, Bouter LM. Corticosteroid injections, physiotherapy, or a wait-and-see policy for lateral epicondylitis: a randomised controlled trial. Lancet 2002;359(9307):657-662.

59. Hay EM, Paterson SM, Lewis M, Hosie G, Croft P. Pragmatic randomised controlled trial of local corticosteroid injection and naproxen for treatment of lateral epicondylitis of elbow in primary care. BMJ 1999;319(7215):964-68.

60. Alfredson H, Ljung BO, Thorsen K, Lorentzon R. In vivo investigation of ECRB tendons with microdialysis technique-No signs of inflammation but high amounts of glutamate in tennis elbow. Acta Orthop Scand 2000;71(5):475-9.

61. Alfredson H, Forsgren S, Thorsen K, Lorentzon R. In vivo microdialysis and immunohistochemical analyses of tendon tissue demonstrated high amounts of free glutamate and glutamate NMDAR1 receptors, but no signs of inflammation, in Jumper's knee. J Orthop Res 2001;19(5):881-886.

62. Di Blasi Z, Harkness E, Ernst E, Georgiou A, Kleijnen J. Influence of context effects on health outcomes: a systematic review. Lancet 2001;357(9258):757-62.

63. Testa M, Rossettini G. Enhance placebo, avoid nocebo: How contextual factors affect physiotherapy outcomes. Man Ther 2016;24:65-74.

64. Rossettini G, Carlino E, Testa M. Clinical relevance of contextual factors as triggers of placebo and nocebo effects in musculoskeletal pain. BMC Musculoskelet Disord 2018;19(1):27.

65. Coombes BK, Bisset L, Vicenzino B. Efficacy and safety of corticosteroid injections and other injections for management of tendinopathy: a systematic review of randomised controlled trials. Lancet 2010;376(9754):1751-67.

66. Quin CE, Binks FA. Tennis-elbow (epicondylalgia externa): treatment with hydrocortisone. Lancet 1954;267(6831):221-223.

67. Coombes BK, Bisset L, Connelly LB, Brooks P, Vicenzino B. Optimising corticosteroid injection for lateral epicondylalgia with the addition of physiotherapy: a protocol for a randomised control trial with placebo comparison. BMC Musculoskelet Disord 2009;10:76.

68. Corrado B, Mazzuoccolo G, Curci L, et al. Treatment of Lateral Epicondylitis with Collagen Injections: a Pilot Study. MLTJ 2019;584-89.

69. Frizziero A, Causero A, Bernasconi S, et al. Efficacy of betamethasone valerate medicated plaster on painful chronic elbow tendinopathy: a double blind, randomized, placebo controlled trial. MLTJ 2016;131-39. 
70. Vicenzino B. Lateral epicondylalgia: a musculoskeletal physiotherapy perspective. Man Ther 2003;8(2):66-79.

71. Hoogvliet P, Randsdorp MS, Dingemanse R, Koes BW, Huisstede BM. Does effectiveness of exercise therapy and mobilisation techniques offer guidance for the treatment of lateral and medial epicondylitis? A systematic review. Br J Sports Med 2013;47(17):1112-9.

72. Fernández-Carnero J, Fernández-de-las-Peñas C, Cleland JA. Immediate hypoalgesic and motor effects after a single cervical spine manipulation in subjects with lateral epicondylalgia. J Manipulative Physiol Ther 2008;31(9):675-81.

73. Giray E, Karali-Bingul D, Akyuz G. The Effectiveness of Kinesiotaping, Sham Taping or Exercises Only in Lateral Epicondylitis Treatment: A Randomized Controlled Study. PM R 2019;11(7):681-93.

74. Cullinane FL, Boocock MG, Trevelyan FC. Is eccentric exercise an effective treatment for lateral epicondylitis? A systematic review. Clin Rehabil 2014;28(1):3-19.

75. Borkholder CD, Hill VA, Fess EE. The efficacy of splinting for lateral epicondylitis: a systematic review. J Hand Ther 2004;17:181-99.

76. Garg R, Adamson GJ, Dawson PA, Shankwiler JA, Pink MM. A prospective randomized study comparing a forearm strap brace versus a wrist splint for the treatment of lateral epicondylitis. J Shoulder Elbow Surg 2010;19(4):508-12.

77. Aydin A, Atiç R. Comparison of extracorporeal shock-wave therapy and wrist-extensor splint application in the treatment of lateral epicondylitis: a prospective randomized controlled study. J Pain Res 2018;11:1459-67.

78. Maffulli G, Iuliano E, Padulo J, Rompe J, Gerdesmeyer L, Maffulli N. Extracorporeal shock wave therapy in the treatment of tennis elbow: the ASSERT database. MLTJ 2018;8(3):423-429.

79. Luk JK, Tsang RC, Leung HB. Lateral epicondylalgia: midlife crisis of a tendon. Hong Kong Med J 2014;20(2):145-51.

80. Waugh EJ. Lateral epicondylalgia or epicondylitis: what's in a name? J Orthop Sports Phys Ther 2005;35:200-202.

81. Di Filippo L, Pennella D, Maselli F, Arrigoni P. Research proposal of a new clinic model for the interpretation of Lateral Elbow Pain: is it time to change? MLTJ 2020;10(1):57-66.

82. Padulo J, Oliva F, Frizziero A, Maffulli N. Muscles, Ligaments and Tendons Journal - Basic principles and recommendations in clinical and field Science Research: 2018 update. MLTJ 2018;8(3):305-307. 


\section{APPENDIX 1}

\section{QUESTIONNAIRES}

Q1 - How many years of experience do you have as a physiotherapist?

- $0-5$

- 5-10

- $10-20$

- $>20$

Q2 - In which job setting do you work?

- Public health system (hospital)

- Private Practice

- Nursing home (private or in convection with the national health system)

- Retirement home

Q3 - How many patients with lateral elbow pain (LEP), a condition also known as tennis elbow or epicondylalgia or lateral epicondylitis, do you visit each month?

- From 0 to 1

- From 1 to 2

- From 2 to 3

- Over 3

Q4 - Which anatomical structures do you think may be the cause of pain in a patient with LEP?

- Common insertion tendon of the extensor muscles of carpus and fingers

- Myotendinous junction of the extensor muscles of carpus and fingers

- Humero-radial and radio-ulnar joint, including surrounding tissues (capsule and ligaments)

- All the structures mentioned above

Q5 - Which clinical tests do you use most often when evaluating a patient with probable LEP? (it is possible to mark more than one box)

- Cozen's Test

- Maudsley Test

- Salt Test

- Pepper Test

- Other (specify)

Q6 - Do you consider that psycho-social factors can significantly influence the natural history and management of the patient with LEP and do you possibly adopt specific strategies in this regard?

- Yes

- $\mathrm{No}$
Q7 - If you answered 'YES' to question 6, which strategies do you use? (it is possible to mark more than one box)

- Pain neurophysiology education

- Cognitive-behavioral approach

- Counseling: encouraging the patient to maintain an active lifestyle

- All the above mentioned

Q8 - In daily clinical practice, which assessment scales and questionnaires do you use with this kind of patient? (it is possible to mark more than one box)

- Patient-Rated Tennis Elbow Evaluation (PRTEE)

- Disabilities of the Arm, Shoulder and Hand (DASH)

- Center for Epidemiological Studies Depression Scale(CES-D)

- Hospital Anxiety and Depression Scale (HADS)

- Other (specify)

Q9 - In your clinical practice, when do you think instrumental diagnostic investigations (MRI, CT, Ultrasound etc.) are useful in some cases of LEP?

- Never

- Always

- In case of significant disability

- In case of visible acute inflammatory signs

- In presence of signs and symptoms that make one suspect of non-physiotherapy competence pathology

- In the case the patient can not be subjected to conservative treatment

- Other (specify)

Q10 - Do you consider surgery a therapeutic alternative in case of LEP lasting for over 6 months?

- Yes

- No

Q11 - Do you consider corticosteroid injections useful in a patient with LEP?

- $\mathrm{NO}$

- Yes, always

- Yes, in patient with LEP in acute phase

- Yes, in chronic patient (over 6 months)

- I do not know

Q12- Which kind of conservative approach to you mostly adopt?

- Therapeutic exercise (TE)

- Manual therapy (MT)

- Protection bracing

- $\mathrm{TE}+\mathrm{MT}$

- $\mathrm{TE}+$ bracing

- MT + bracing

- $\mathrm{TE}+\mathrm{MT}+$ bracing 


\section{APPENDIX 2}

\section{INFORMATION LETTER}

Dear colleague,

I ask for your collaboration for the achievement of a prevalence observational study which aims to investigate the methods of approach used by Italian physiotherapists in the assessment and management of lateral elbow pain (LEP).

This study has already obtained the approval of the Ethics Committee of Lecce (ASL Lecce, Minutes n.30, 7 March 2019 - Elbow Lateral Pain Survey) and is entirely conducted by the University of Rome "Tor Vergata" - Master's Degree in Applied Manual Therapy to Physiotherapy.

Therefore, we submit a simple questionnaire of 12 questions, made on the basis of the most recent scientific literature in collaboration with the following colleagues: Brindisino Fabrizio, Di Filippo Luigi, Maselli Filippo, Pennella Denis and Salomon Mattia.

Reading and completing the questionnaire anonymously takes only three minutes.

(link: https://it.surveymonkey.com/r/5P8SRLW)

Trusting in your collaboration, thank you and kindly best regards. 